\title{
Enhancing Secondary School Students' Understanding of Descriptive Statistics Using a Modeling Instructional Approach
}

\author{
Mulugeta Woldemicheal Gebresenbet ${ }^{1}$, Mulugeta Atnafu Ayele ${ }^{2}$ \\ ${ }^{1}$ Department of Mathematics, College of Science, Dire Dawa University, Dire Dawa, Ethiopia \\ ${ }^{2}$ Department of Science \& Mathematics Education, Addis Ababa University, Addis Ababa, Ethiopia
}

Email address:

mulugeta1721@gmail.com (M. W. Gebresenbet), ayatmu@yahoo.com (M. A. Ayele)

\section{To cite this article:}

Mulugeta Woldemicheal Gebresenbet, Mulugeta Atnafu Ayele. Enhancing Secondary School Students' Understanding of Descriptive Statistics Using a Modeling Instructional Approach. Education Journal. Vol. 6, No. 1, 2017, pp. 5-21. doi: 10.11648/j.edu.20170601.12

Received: October 12, 2016; Accepted: October 27, 2016; Published: January 10, 2017

\begin{abstract}
The purpose of this study is to explain how secondary students can enhance their understanding of descriptive statistics using Modeling Approach and to what extent do students improve their achievement of procedural and conceptual understanding in descriptive statistics using Modeling Instructional Approach. The study was conducted at two secondary schools in urban district in West Oromia Zone, Ethiopia. For comparisons, four grade nine sections with a total of 163 students were selected by purposive sampling technique. Quality Assurance Guide instrument was used to assess students' models on Model Eliciting Activities (MEA). Standard questions were used for achievement tests on procedural and conceptual understanding of descriptive statistics. The quantitative data of the study was analyzed using descriptive statistics, and independent t-test. The qualitative data of the study was analyzed using thematic and content analyses. The findings of this study are: though students found MEAs cognitively challenging tasks, they constructed different models working in a team collaboratively. The study showed students more likely can enhance their critical understanding of descriptive statistics and gain modeling experiences working on relevant non-routine tasks like MEAs and doing project on their own themes. Also a statistically significant difference was found on conceptual understanding achievement test with medium effect size using Modeling Approach, but no statistical significant difference was found on procedural understanding achievement test except female comparison. The findings of this study suggested students more likely enhanced their understanding of descriptive statistics using Modeling Approach.
\end{abstract}

Keywords: Descriptive Statistics, Non-Routine Problems, Model-Eliciting Activities, Understanding, Achievement

\section{Introduction}

Modeling, as an alternative for problem solving, is getting recognition in Mathematics Education for advancing students' understanding of a concept. However, research studies are needed on how to incorporate modeling problems in an education system so as to enhance students' understanding of concepts and thereby improve students' achievements. Therefore, in this study, teaching statistics using Modeling Approach, which establishes the problem leading to the study, is discussed. The background of the study, theoretical framework and modeling research, statement of the problem, objective and research question of the study, significance of the study, and delimitations of the study are described.

\subsection{Background of the Study}

Teaching through problem solving considers problem solving as integral to the development of an understanding of any given mathematical content and process [1]. It is different from the practice of teaching for problem solving which deals with solving problems using the already taught concepts. It also differs from teaching about problem solving which deals with problem solving heuristics and strategies. A Modeling Approach in the study integrates Contextual and Socio-critical Modeling Perspectives for teaching statistics through problem solving and, therefore; justifies the statistics rather than treating it as a means to an end. 
Modeling problems could help enhancing students' critical understanding to deal with problems of socio-cultural and environmental complex systems [2]. How far problems in textbooks contribute for critical literacy aim and how teachers utilize such problems that could promote critical understanding is an under researched area in mathematics education [3]. What remains to be explored is to study on mathematical or statistical modeling as a critical tool for enhancing students' critical understanding of mathematics or statistics [4].

Specifically, across all walks of life, statistics is essential for understanding the world and serves as a critical tool for solving socio-cultural problems. For example, the modeling ability to interpret, describe, and explain data and communicate results of data analysis is crucial in day to day life [5]. One way to promote statistical reasoning is through data modeling [6]. However, there are very few studies that promote students' statistical thinking and reasoning at school using data modeling [1, 7]. According to Sriraman and English [8], the issue of enhancing students' statistical reasoning through data modeling requires 'substantial research'.

If students gain the habit of working on statistical problems using models of representation systems, then models as thinking tools will help students to develop statistical reasoning and problem solving abilities. Cobb [9] argues that, "Data sets are concrete, statistical models are abstracts, and every instant of modeling is an instance of abstraction-as a process". However, surprisingly, there is little research on models and modeling in Statistics Education [10].

A major goal of mathematics education in Ethiopia is to develop problem-solving abilities of students in sociocultural context of their everyday life which is stated in different official documents $[11,12]$. Descriptive statistics is part of Ethiopian secondary school mathematics curriculum with the aim of teaching students for developing foundational concepts of statistics to solve problems related with 'every bit of students' everyday life' [13].

The percentages of exercises and word problems tasks in statistics unit in Ethiopian Grade Nine mathematics textbook are $68 \%$ and $27 \%$ respectively. Although Ethiopian education policy and documents on mathematical curriculum recommend that there should be relevant problem solving activities on socio-cultural issues, the percentage of statistical problem solving tasks (4\%) in Grade Nine textbook is very low and non-routine statistical problem solving tasks are almost non-existent. Researchers have indicated that covering the text book is the most common teaching practice in Ethiopia instead of engaging students with rich problemsolving tasks [14]. This may lead teachers to use simple textbooks problems, and as a result students couldn't develop cognitive abilities to solve problems in novel situations.

\subsection{Theoretical Framework and Modeling Research}

\subsubsection{Contextual Modeling Perspective}

It is for the purpose of motivating students in mathematics activities using real life problems and for developing their strategic competence to solve real world problems brought modeling come into existence in schools [15]. Because modeling activities starts from meaningful real life situations, students could develop positive dispositions towards the subject. Contextual Modeling also known as Models and Modeling Perspective established as theoretical perspective from research studies that have been done for more than three decades by Lesh and his colleagues $[16,17]$. It blends two important, but separate research traditions in mathematics education: problem solving and conceptual development. That means, students would enhance their understanding of a concept as they solve modeling problems simultaneously. In this research the use of the term "mathematics" found in and referred to in Contextual and Socio-critical Modeling Perspectives literature includes statistics.

Theoretical perspectives for Contextual Modeling Perspective research begin their roots from the perspectives of Piaget, Vygotsky and American Pragmatists such as William James, Charles Sanders Peirce, Oliver Wendell Holmes, George Herbert Mead, and John Dewey [18]. It is taken as a framework for developing models of students' modeling. A model in this perspective is defined as "a system of describing or (explaining, or designing) another system(s) for clearly specified purpose [19]."

Like Piaget, the perspective focuses on the development of elementary but deep cognitive structures with holistic characteristics that are not derived from characteristics of constituent parts [20]. It considers mathematics as the study of structures and the conceptual systems are with-in or between concept systems [21]. In Models and Modeling Perspective, conceptual development is far more piecemeal and situated than Pigetians suggest. It considers the term 'decalage' that Piaget used for ladder like a sequence of development stages from concrete to abstract understanding as fuzzy, poorly differentiated which occurs along a variety of dimensions: concrete-abstract, simple-complex, situateddecontextualized, external-internal, specific-general, intuitive-formal, and unstable-stable [19].

A Contextual Modeling perspective would consider students learning by putting them in situations where they express their current ways of thinking in forms that will be tested and revised in directions of increasing power without introducing the concepts as if they are new ideas following some other idea [16]. For instance, to teach the interconnected concepts like center, variability and distributions in descriptive statistics, it considers most students could be at intermediate stage of development for such concepts that it may not be good to teach them sequentially like 'topic-topic-topic' approach. A central goal of the perspective is to facilitate students' development and refinement of their own abilities to interpret situations mathematically (statistically).

Statistical concepts in descriptive statistics are difficult to learn because they are abstract [10]. So it would be possible to teach students by creating a learning situation through multiple dimensions of model development. For example, to 
learn about the statistical concept of mean, students could start from their own intuitive definitions, work on concrete activities like post-it note activities considering mean as a balance point, discussing its meaning on a media article and on textbooks and so on.

In Contextual Modeling Perspective models could be expressed in external representation systems and they could be outside the mind. This is the case where it obviously differs from constructivism [22]. The perspective recognize that the only way that anybody can have access to another person's internal conceptual system is when they are expressed using some expressed media or representation systems [16].

\subsubsection{Modeling Research}

There were only a few studies conducted on models and modeling processes in Statistics Education [10], but some studies using MEAs had been conducted and the relevant studies related to statistics education would be reviewed to answer the review question. The research background on the effectiveness of MEAs built on five areas: research on the use of MEAs in Science, Technology, Engineering and mathematics (STEM) areas which includes statistics; invention to learn activities and research on gifted education; the role of prior knowledge; and research on problem-based learning research on equity education.

MEAs possess specific qualities that ask students to engage in multiple iterations to solve the problem similar to the engineering design process [5]. The process of creating and refining multiple iterations of the models has been referred to as the process of, 'express, test, and revise' [23] in an attempt to seek a highly refined mathematical model. Magiera [24] argued that MEAs have provided problemsolving experiences that help a wide range of mathematical expertise that creates problem solvers, innovators, inventors, self motivation and self reliance, logical thinkers, technological literacy which supports the goal of STEM. Researchers had found dramatic and positive results using MEAs in STEM education at different school levels [25, 1, 26, 27].

Statistics Education research studies had indicated that MEAs promote statistical reasoning and thinking at upper primary and at introductory statistics courses. By considering a real world problem, a set of data, the need for a solution, students would experience the statistical enquiry cycle [28] as they solve MEAs problems. Doer and English [29] investigated students at primary were able to create generalizable and reusable systems or models for selecting, ranking, and weighting data.

To offer students statistical problem solving based on real data Garfield, delMas and Zieffler [30] showed how to develop MEAs funded by the CATALST (Change Agents for Teaching and Learning Statistics) project. Noll, Gebresenbet and Glover [31], using CATALST curriculum that involve MEAs, explored various ways to support students' thinking and to help them answer informal statistical inference questions in introductory statistics using dynamic statistical software. MEAs have recently been shown to be effective in statistics education for catalyzing group discourse during cooperative learning $[32,33]$.

Cognitive researcher had found that students' prior knowledge and institution had conflict with new learning [34]. Research suggested that the need for learning activities that help students work through inconsistencies in their prior knowledge and intuitions while at the same time building the scaffolding for future learning [34]. MEAs have been designed explicitly to reveal and test students' intuition and prior knowledge while at the same time providing for extensions, revision, integration of these ideas to develop a foundation for more abstract, formal ways of understanding [35].

MEAs are primarily used to investigate students' thinking and hold great potential in situation in which other assessment techniques fall short; a huge void is left in understanding why students come up with the answers that they do [5]. MEAs are typically used to 'plow the field' so that seeds of learning more formal content may be planted [30]. Researchers recommended that MEAs provides a richer set of assessment data [5, 17].

\subsection{Statement of the Problem}

According to Word Bank report [36], the quality of learning outcomes in developing countries has been poor. Ethiopia, one of the developing countries, has conducted four round national learning assessments on key subjects that includes mathematics in 2010 and 2013 for grade 10 and 12 students. Both the two assessments have showed that secondary students' average achievement scores in mathematics were found to be low; and most students in secondary grade could not score at least $50 \%$ in mathematics [37, 38].

Traditionally, statistical curricula follow 'linear and hierarchical approach' to teach students foundational statistics concepts adopting from the formalist mathematics culture [39]. For example, many students are taught about data distribution, measure of center, and variation sequentially on how to construct them rather than how to use them to think with data.

Modeling needs to be integrated within all topic areas across the mathematics curriculum, and, there is a need, across disciplines [1, 40]. There is, however, a limited research on how to integrate other disciplines within mathematics curriculum which can be done through modeling instruction $[1,26]$. Modeling, as an alternative for problem solving, is getting recognition in Mathematics Education for advancing students' understanding of a concept [8]. However, research studies are needed on how to incorporate modeling problems in an education system so as to enhance students' understanding of concepts and thereby improve students' achievements [20]; and little is known about Socio-critical Modeling that uses mathematics or statistics as a critical tool for analyzing and solving sociocultural problems [3].

The more teachers incorporate and implement relevant 
non-routine real-world problems within the curriculum, the better their chances of enhancing secondary students' understanding of descriptive statistics by giving them an opportunity to develop their sense making and explain their reasoning iteratively. Using Modeling Approach, student could construct, revise and refine models; and they may enhance their understanding of descriptive statistics and apply statistics as a critical tool with positive attitude to solve problems in socio-cultural problems.

\subsection{Objectives of the Study}

The major objective of this study is to explain how secondary students can enhance their understanding of descriptive statistics using Modeling Approach and to what extent do students improve their achievement procedural and conceptual understanding in descriptive statistics using Modeling Instructional Approach. The specific objectives of the study were:

To explain how secondary students can enhance their understanding of descriptive statistics using Modeling Approach

To assess the extent of secondary students improve their achievement of procedural and conceptual understanding in descriptive statistics using Modeling Instructional Approach

\subsection{Research Questions}

Based on the above objectives the following research questions are tested in the study.

1. How secondary students can enhance their understanding of descriptive statistics using Modeling Approach?

2. There is no significant mean scores difference between students who have learnt using Modeling and Nonmodeling Approach on achievement of pretest, posttest, procedural and conceptual understanding of descriptive statistics.

\subsection{Significance of the Study}

A study of the Modeling Approach to teach statistics is important for several reasons. First, it helps to lay the ground for further similar empirical studies across different school settings and populations on how to enhance students' understanding of descriptive statistics. Second, it serves as a basis for further effectiveness and large scale studies for teaching statistics using Modeling Approach. Third, the study will show research directions on how to design curriculum using transformative modeling framework in order to teach students with social justice aim using statistics as a critical tool. Fourth, it will help teachers as a heuristic devise on how to prepare and implement relevant non-routine problem solving tasks like MEAs. Fifth, the study will provide directions on aspects of professional development that have to be given for teachers for teaching statistics in secondary schools. Finally, it will serve as an available asset for policy decision makers, curriculum developer, and assessment builders on how to include relevant non-routine problem solving tasks in an education system.

\subsection{Delimitations of the Study}

This study is conducted in under-privileged urban secondary schools setting in West Oromia Zone in Ethiopia. It focuses on one statistics unit that contains descriptive statistics lessons. The descriptive statistics deals with basic ideas of data, distribution, center and variability. The study site is delimited to one district in two governmental secondary schools in non-technological school learning environment except the use of calculators, post it notes and plastic meters.

\subsection{Structure of the Study}

This study covers five main topics. The first topic introduced the background of the study, theoretical framework and modeling research, statement of the problem, objective and research question of the study, significance of the study, and delimitations of the study. The second topic establishes the study's materials and methods and provides research approach and design and a rationale for using transformative embedded mixed method research, the sampling techniques and participants, instructional design for the modeling approach, instruments of data collection, validity and reliability of the instruments and data analysis. The third topic presents and discusses on Modeling Approach intervention based on classroom observation and students' reports on MEAs. Then, this topic presents and discusses on students' achievements based on quantitative students' scores data on procedural and conceptual understanding achievement tests of descriptive statistics. The fourth topic discusses on the general findings of qualitative and quantitative data towards answering the leading research question in the study. The fifth topic ends with conclusions and recommendations of the study for research and practice.

\section{Materials and Methods}

This topic presents the research approach and methods used to investigate secondary students' understanding of descriptive statistics using Modeling Approach. A transformative embedded mixed design in a pragmatism paradigm underpinned this study. To answer the research questions and to test the hypotheses, a transformative embedded mixed research design with lens of two modeling perspectives were used.

\subsection{Research Approach and Design}

The research problems of this study led a transformative embedded mixed method approach both quantitative and qualitative forms to be utilized [41]. The rationale for choosing the research approach was the nature of the mixed research question; that is, to what extent and how students' enhance their understanding of descriptive statistics using Modeling Approach. To investigate to what extent and how students' enhance their understanding of descriptive statistics 
using Modeling Approach may be complex at classroom level which involves intertwined understanding strands that may require simplification of discrete variables and more holistic qualitative approach.

The transformative embedded mixed design in this study used quasi-experimental design for collecting quantitative data using achievement tests. The rationale for using quasiexperimental design is to compare the effect of teaching approaches in the natural school setting, not by assigning students to random or equated groups but by following students in groups formed by their schools and using statistical methods to control for prior achievement [42]. To test the research hypothesis, the quasi-experimental design used in this study is known as non-equivalent control group pretest and posttest design as shown below.

$\begin{array}{lllll}\text { Experimental Group: } & \mathrm{NR} & \mathrm{O}_{1} & \mathrm{X} & \mathrm{O}_{2} \\ \text { Control Group: } & \mathrm{NR} & \mathrm{O}_{1} & & \mathrm{O}_{2}\end{array}$

In this design, NR represents non-randomization, $\mathrm{O}_{1}$ represents pretest, $\mathrm{X}$ represent the treatment implemented, and $\mathrm{O}_{2}$ represent the posttest [43]. For explaining the intervention (the Modeling Approach), case study design was used based on the data that included students' solution artifacts on MEAs. The case study used was explanatory type to answer the how research questions on students' understanding of descriptive statistics using Modeling Approach [44]. The unit of analysis in this study was classroom practices of Modeling Approach, teams of students who participated on the intervention to investigate how students' enhance their understanding of descriptive statistics. Besides, means of students' achievement scores on procedural and conceptual understanding were compared.

\subsection{Sampling Techniques and Participants}

This study was conducted at West Oromia Region schools (School A and School B; pseudonyms) in Ethiopia based on grade 9 secondary mathematics school curriculum which had one unit of descriptive statistics with 22 period allotments. From the two high schools, 163 students participated in this study from four grade 9 sections. Two teachers were selected one from school A, and the other from school B based on their willingness to participate in the research, and then two non-equivalent intact grade 9 classes from each school taught by the selected teacher were selected. The sampling method used to select the four classes for the quasi-experimental design was purposive sampling because the method would allow creating intact classroom group for the quasi experimental design. Lottery method was used to assign classes for Modeling and Nonmodeling Approaches in the two schools. In both schools, one class of students was taught using Modeling Instructional Approach and the other as a comparison class was taught using Non-Modeling Instructional Approach.

\subsection{Instructional Design for the Modeling Approach}

Three MEAs were designed for this study as described in Table 1 based on the six principles of constructing MEAs [16] with other statistical activities using representations systems. The MEAs had four main components: newspaper article, readiness or warm up questions, data table, and a problem statement. Each component serves a valid purpose and used to engage problem solvers in the task [45].

Table 1. Descriptions of the four Model Eliciting Activities.

\begin{tabular}{|c|c|c|c|}
\hline Title of MEA & Problem Context & Statistical Concept & Objectives with Social Agency \\
\hline Safe-Water & $\begin{array}{l}\text { Students are asked to write a report based on } 20 \text { households data } \\
\text { to give an awareness program for rural people how to drink safe } \\
\text { water and keep their environment sanitation and hygiene. }\end{array}$ & $\begin{array}{l}\text { Different graphs, distribution, } \\
\text { average, little or a lot } \\
\text { variability }\end{array}$ & $\begin{array}{l}\text { To provide awareness on health } \\
\text { and sanitation problems }\end{array}$ \\
\hline $\begin{array}{l}\text { Millennium } \\
\text { Dam }\end{array}$ & $\begin{array}{l}\text { Students are asked to write a report based on three grade } 9 \\
\text { sections of students' data on the contribution of money to } \\
\text { Ethiopian Millennium dam which is going to be sent by the } \\
\text { director for the news agency. }\end{array}$ & $\begin{array}{l}\text { Outliers, measure of centers } \\
\text { (mean, median and mode) } \\
\text { Range }\end{array}$ & $\begin{array}{l}\text { Empower students on their } \\
\text { contribution for developing their } \\
\text { identity }\end{array}$ \\
\hline Tourist & $\begin{array}{l}\text { Students are asked to give reliable information based on the } \\
\text { weather data of five tourist sites on what to eat, cloth and shoes } \\
\text { to wear. }\end{array}$ & $\begin{array}{l}\text { Distribution, measure of } \\
\text { center, measure of variation }\end{array}$ & $\begin{array}{l}\text { Use variability in everyday life like } \\
\text { knowing variability of weather } \\
\text { conditions }\end{array}$ \\
\hline
\end{tabular}

The purpose of the newspaper was to familiarize students with the context of the problem and to develop their statistical literacy. This article required 15 minutes or so to read and provide further information for the second part of MEAs. The second part of an MEA was readiness questions or warm-up questions. These questions were designed to evaluate their understanding of their reading and basic statistical literacy ability of the media article. The third part of MEA was a problem statement which required students pose and solve problems on the socio-cultural problem situations. The fourth part of an MEA was usually a data table that may be used to solve the problem. After finishing the MEA, there would be other follow up activities that used system of representations and MEA extension problems. For example, in Safe-Water MEA students were introduce other graphs from simple graph type dot plot to histogram and how to interpret by comparing distribution of various graphs. Then, as assignment students wrote a report for Ministry of Water and Energy on Safe-Water MEA based on their own data and got feedback on the structural similarity of the pervious client report on Safe-Water MEA. Students were expected to use the newly introduced representation systems in the MEA extension problem.

\subsection{Instruments of Data Collection}

\subsubsection{Probing Work-Sheet for MEAs}

Based on the modeling cycle, a worksheet with the 
following probing questions were prepared and given for the students: What is the thing that the client wants you to do for him/her? How could you use the data using your model so that it is meaningful for the client purpose? Could you show how to use the statistical models to provide some solution for the problem? What are your interpretations on the models you made in question 3? Do you think your statistical models enough for the client purpose and have limitations? Write your team report/letter/news.

\section{Quality Assurance Guide}

The quality assurance Guide was designed to help teachers, researcher and students evaluate the products that were developed in response to the MEAs with the following characteristics: (a) the goal is to develop conceptual tools, (b) the client purposes are known and met, and (c) the tool must be sharable with other people and must be useful in situations where the data are different than those specified in the problem as shown in Table 2.

Table 2. Quality Assurance Guide.

\begin{tabular}{|c|c|c|}
\hline Performance Level & How useful is the product? & What might the client say? \\
\hline Level one: Require Redirection & $\begin{array}{l}\text { The product is on the wrong track. Working longer or harder } \\
\text { won't work. The students may require some additional feedback } \\
\text { from the teacher. }\end{array}$ & $\begin{array}{l}\text { "Start over. This won't work. Think about it } \\
\text { differently. Use different ideas or procedures. }\end{array}$ \\
\hline $\begin{array}{l}\text { Level two: Require Major } \\
\text { Extensions or Refinements }\end{array}$ & $\begin{array}{l}\text { The product is a good start toward meeting the client's needs, but } \\
\text { a lot more work is needed to respond to all of the issues. }\end{array}$ & $\begin{array}{l}\text { "You're on the right track, but this still needs a lot } \\
\text { more work before it'll be a form that's useful." }\end{array}$ \\
\hline $\begin{array}{l}\text { Level three: Requires only } \\
\text { Minor Editing }\end{array}$ & $\begin{array}{l}\text { The product is nearly ready to be used. It still needs a few small } \\
\text { modifications, additions, or refinements. }\end{array}$ & $\begin{array}{l}\text { "Hmmm, this is close to what I need. You just } \\
\text { need to add or change a few small things." }\end{array}$ \\
\hline $\begin{array}{l}\text { Level four: Useful for this } \\
\text { Specific Data Given }\end{array}$ & $\begin{array}{l}\text { No changes will be needed to meets the immediate needs of the } \\
\text { client. }\end{array}$ & $\begin{array}{l}\text { "Ahhh, this will work well as it is, I won't even } \\
\text { need to do anything". }\end{array}$ \\
\hline $\begin{array}{l}\text { Level five: Sharable or } \\
\text { Reusable }\end{array}$ & $\begin{array}{l}\text { The tool not only works for the immediate situation, but it also } \\
\text { would be easy for others to modify and use in similar situations }\end{array}$ & $\begin{array}{l}\text { "Excellent, this tool will be easy for me to modify } \\
\text { or use in other similar situations-when the data are } \\
\text { slightly different." }\end{array}$ \\
\hline
\end{tabular}

The Quality Assurance Guide was used to quantitatively assess students' models. The levels were designed to categorize how well students' solution artifacts or reports satisfy the needs of the client and how well they explained their reports in general way [35]. The range of response went from level 5, where the response satisfied the needs of the client for the current situation and for other similar situations as well, 1, where the response were going in the wrong direction and the team would need to rethink their reports completely.

\subsubsection{Pretest and Posttest Assessments}

To investigate the extent of prior statistical knowledge differences between Modeling and Non-modeling groups, an assessment was designed from Ethiopian National Primary Leaving Mathematics Examinations by selecting 15 questions related to basic statistics concepts from year 20082014. This assessment which was used as a pretest contained 15 items and all were closed ended multiple choice items. The items dealt with basic concepts of reading graphs like pie chart, bar graphs and calculating percentage, mean, median and mode. Two posttests assessments were used to compare students' procedural and conceptual understanding of descriptive statistics after they learnt descriptive statistics unit. The posttest on procedural understanding had been collected from Ethiopian Secondary Leaving National Mathematics Examination from 2008 to 2014. The test contained 15 closed ended multiple choice items and the questions asked were procedural questions for calculating measure of center and measure of variation, identifying primary and secondary data, and reading information from bar graph. The other posttest given was on students' conceptual understanding of descriptive statistics. The items contained 15 closed-ended multiple choice items and selected from the ARTIST website which includes statistical reasoning assessment items on descriptive statistics. ARTIST assessment items were created for assessing statistical literacy, reasoning and thinking [10]. The researchers adopted the ARTIST assessment items related with the conceptual understanding of descriptive statistics.

\subsection{Validity and Reliability}

Content and face validity were used for this study. The instruments were provided for experts in the field to review the instrument and for language experts if there were any difficulty in the language use. Finally, 10 teachers at three schools who taught the lesson were asked to give comments on pretest and posttests of the achievement instruments. Test items which did not fit the purpose were dropped based on experts and teachers comments. Test-retest reliability tests were used to check the reliability of achievement tests on the intervention. The students in the pilot study took the tests and one week later took the same test again. A test-retest reliability analysis yielded a reliability of 0.85 for achievement pre-test, 0.71 for posttest in procedural understanding achievement test and 0.75 for conceptual understanding achievement test. Triangulation, peer review and debriefing, negative case analysis, clarification of researcher bias, member checking, and external audit was used for the qualitative data.

\subsection{Method of Data Analysis}

Both quantitative and qualitative data collection methods 
administered during and after the implementation of the Modeling instruction. The source of data for the research was students' reports on the four MEAs and achievement tests. Content analysis of teams of students' models on the four MEAs was made using Quality Assurance Guide. Descriptive statistics such as means and standard deviations of pretests and posttests students' scores were reported. Data on achievement tests on procedural and conceptual understanding of descriptive statistics were analyzed using ttest based on the statistical assumptions.

\section{Results}

The result is on Modeling Approach intervention based on students' models on the MEAs with follow up activities to answer the research question on how students enhance their understanding of descriptive statistics using Modeling Approach.

\subsection{Students' Models for MEAs}

\subsubsection{Students'Models for Safe-Wate MEA}

For safe-water MEA a newspaper article with title 'ETHIOPIA: Safe water - a glass half full' is given as a reading homework to students. For the next class readiness or warm up questions were given for discussion like: How is water treated in your family? Do you drink tap water, boiled water, spring water or rain water? How many glasses of water do you drink per day in average? Explain. Have you ever seen or heard about how Ethiopian rural people fetch and treat drinking water? What do you think children under the age of 5 are much more vulnerable for water born diseases? Next students were introduced different types of graphs and interpreted by comparing distribution of various graphs. Finally, students were given a data table on 'Demography and background information for 20 families' households' and asked to write the report and prepare the posters. Therefore, below are the responses of students' model at different levels.

a) Students' Models at Level 1: Safe-Water MEA: Two teams of students were at level 1on Safe-Water MEA. The reports were unrelated to the clients' needs and did not fit the purpose of the task. For example, one team of students drew the bar graph as shown in Figure 1 and a report. First, they drew the bar graph putting on the $\mathrm{x}$-axis the name of the representative of the 20 householders. Then, they drew the annual income of householders in thousands on the y-axis. The report and a bar graph presented by the team of the students' model on Safe-Water MEA at Level 1 were as follows.

Report: Dear Ladies and Gentlemen, today we will give you an awareness program on keeping the sanitation of latrine houses. We have drawn a bar graph with the income of family in thousand birr and the number of children whose age are greater than or equal to the age of 5 years old. From the graph, we see that a family with 22 thousand birr income has 4 children, a family with 15 thousand birr income has again 4 children and a family who has 40 thousand birr income has 5 children and so on. Each family has better income and at least has 2 children at home. Thus, a family should keep the latrine clean together and should not use open deification and wash hands after going to latrine house. We thank you for your attention!

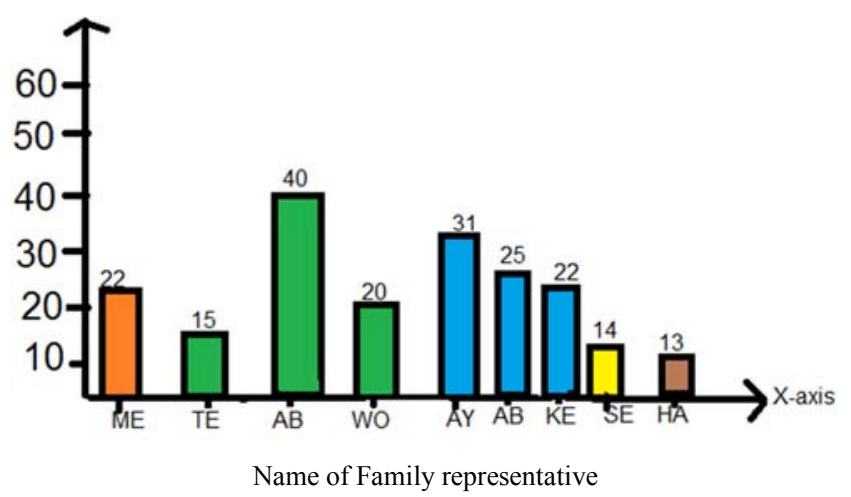

Figure 1. Team of students' model on Safe-Water MEA at Level 1.

They tried to modify the graph putting the income of householders on the x-axis and the number of children on the y-axis. But, they couldn't justify why they drew the graph. In addition, the report merely included little data from the provided data table and partial data was used for the bar graph. The report needs a complete redirection.

b) Students' Models at Level 2: Safe-Water MEA: Seven teams' of students were at this level. One team of students' drew pie chart on drinking water sources and histogram on the number of families whose age was greater or equal to 5 as shown in Figure 2. The team drew a histogram with the bars overlapping, but the variable on the $\mathrm{x}$-axis was a discrete variable. The team showed meaningful interpretation, though they selected only two variables. The work was on the right direction, but it needs adjustment to satisfy the clients' needs. The team had to redraw the histogram by labeling the axis and making the bars non-overlapping. The report and a histogram presented by the team of the students' model on Safe-Water MEA at Level 2 were given below.

Report: Good morning! Today, we will see how to treat drinking water in a family. Based on our data as shown in the pie chart, for 20 householder families $40 \%$ of drinking water source is protected well, 35\% -borehole, $15 \%$ spring and $10 \%$ comes from rain water. The histogram has also showed the number of family members whose age is greater or equal to 5 . There are 3 householders who have 2 family members, 6 householders who have 3 family members, 5 house holders have 4 family members and another 5 householders have 5 members and one householder have the maximum number of family members which is 6 . Dear families, the water you drink is not well treated which causes many water born diseases like typhoid and typhus. We should first boil the water and then cool it for drinking purpose. Every family member should feel responsible for keeping the water safe. We thank you for listening! 

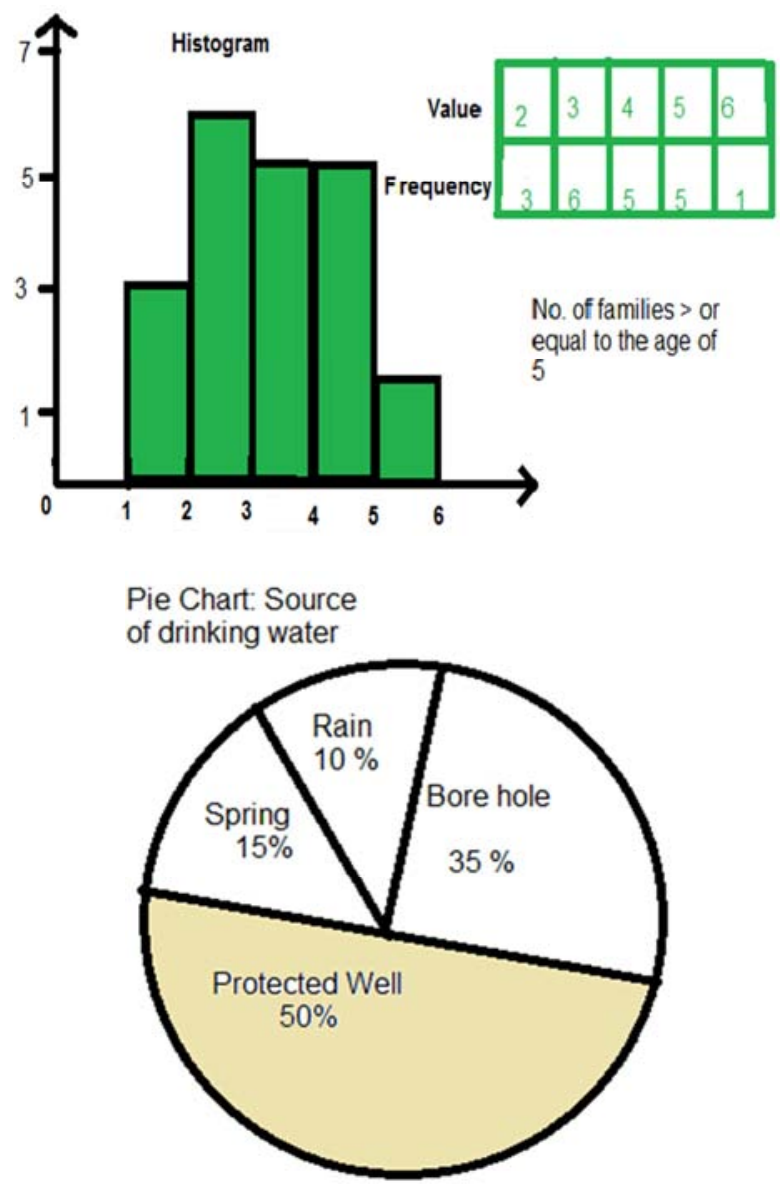

Figure 2. Team of students' model on Safe-Water MEA at Level 2.

c) Students' Models at Level 3: Safe-Water MEA: Nine teams of students were at level 3. Teams of students' reports at this level were closely ready to give an awareness program on safe drinking water, but the reports needs some modifications. Among these teams of students, one team of students prepared a report on safe drinking water on how to wash hands after using a latrine as shown in Figure 3 . The two bar graphs and the pie charts were appropriate and visible except they need titles. The interpretations on the graphs were correct and used more than three variables unlike the students' models at Level 2. The report and a histogram presented by the team of the students' model on Safe-Water MEA at Level 3 were given below.

Report: Welcome! How are you? We are going to discuss with you on keeping our environment sanitation and on how to give our children safe drinking water based on data and graphs. As the graph shows, out of 20 householders' in our rural community, there are 8 householders who have used protected well for drinking water source, 2 householders use rain water, 3 from spring and 7 get from Borehole water source. There are family members who do not wash their hands. For example, out of 9 people 6 people do not wash hands taking 9 householders sample from the 20 householders. This is a serious matter because $50 \%$ of householders in the community use open defecation. Hence based on the data we need a solution to keep our children safe because every family have at least one child except two householders. Children are most affected by unsafe water. We recommend the following solution: (1) All people have to wash their hands, and (2) All people have to save the children. Next time we will see how to filter and treat the water.

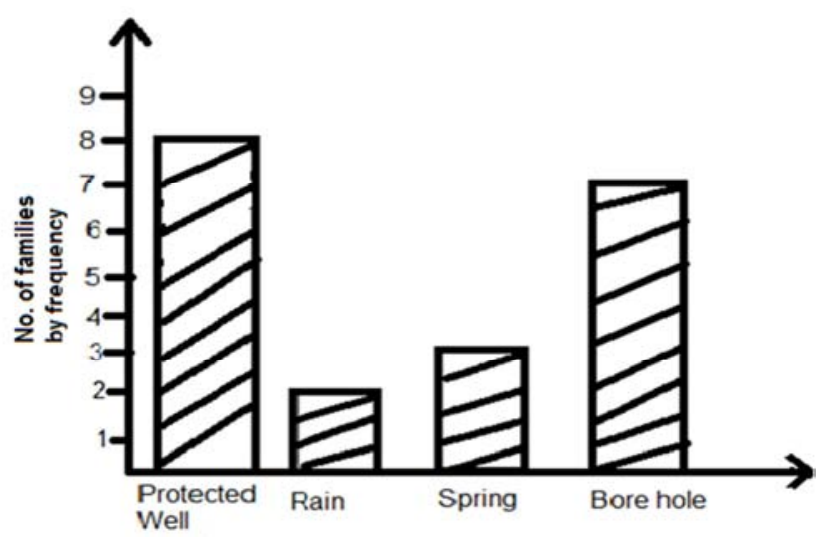

Figure 3. Team of students' model on Safe-Water MEA at Level 3.

d) Students' Models at Level 4: Safe-Water MEA: One team of students' was at level 4 . The team wrote the report to give an awareness program for the society. The team drew histogram for the income of the householders for 20 families and the income ranges from 13 thousand birr to 90 thousand birr. They also drew bar graphs and pie charts. Then, they made association with the area each householders had in its compounds. They could see the paradox in that the area the 20 householders own was large and they had high incomes. But, half of the householders with their family practiced open deification. This was interesting, because they had created relations among the variables looking at some data pattern. But, the report might not be sharable or reusable if the data provided or the context was different. The report presented by the team of the students' model on Safe-Water MEA at Level 4 was given below.

Report: Dear Ladies and Gentlemen, Good morning! We have called you to solve the problems the community have for building the latrine and keeping our environment safe and wash our hands. Based on our data we found that 20 householders had better income and enough area. The people income ranges from 13 thousand birr to 90 thousand birr yearly. It surprises us because half of them (50\%) practice open defecation and lack no latrine houses. Most of the people use water sources like protected well (40\%), borehole $(35 \%)$, spring water $(15 \%)$, and rain water $(10 \%)$. All of this water sources may contain impurities and should be treated. But, we need also to build pump water or ask the government to get tap water service. So we need to solve the problem together. How could we create awareness for every member of our family young and old to wash hands? How we build latrines in our compound? And how do we get safe drinking water? Please, give us your comments if you have any better options!

\subsubsection{Students' Models for Millennium Dam MEA}

The second MEA is on Millennium Dam with title 'Dams 
and hydropower in Ethiopia' is given as a reading homework to students and followed by readiness or warm up questions for discussion such as: What is the average capacity of hydropower plants commissioning before 2012? What will be the average capacity of hydropower commissioning in between 2012 to 2015? Compare your answer with the first question. Which contractor has done the most hydropower plants in Ethiopia? Which country or organization supports Ethiopia most in constructing hydropower plants in terms of cost? And "Poverty is our number one enemy!" Explain the pros and cons of using hydropower plants in Ethiopia in relation to our poverty? Next students were given a data table on 'the contribution made by Karamara secondary High school students in three grade 9 sections to build the Millennium dam which is collected by the school record office' and asked to write the report. Therefore, below are the responses of students' model at different levels.

a) Students' Model at Level 1: Millennium Dam MEA: Two teams of students were at this level. One team wrote the report without meeting the client's needs as shown below in the report, because the director wanted a news report to be given for a news agency based on three Grade 9 sections money contribution for the Millennium dam. The models needed to be done again with teacher's feedbacks. The report presented by the team of the students' model on Millennium dam at Level 1 was given below.

NEWS: Secondary Students in School A contribute money for the Millennium Ethiopian dam by buying a bond of 2415 birr. The school director Teshome Bikila told the media that it is not the first time for students to buy bonds for the Millennium dam. He explained that the students' strong contribution will continue in the future. Some students stated that besides their education they are ready to give support for the country's continuing development and be there to give the necessary help. They said that this bond buying is one part of ensuring the country's development. We present the details as we get more on the NEWS!

b) Students' Model at Level 2: Millennium Dam MEA: Four teams of students were at this level. One team of students' report included the number of the participation of girls and boys as shown below in the news. The report did not include other data like what were sources of money the students got to contribute for the Millennium dam and the age of students who made contribution. The report presented by the team of the students' model on Millennium dam at Level 2 was given below.

NEWS: Here are the breaking NEWS! First the headlines! Secondary students in school A have contributed money for the Millennium dam. I am Alexander Fikadu, the presenter. Stay with us! In Oromia town, students in secondary school have supported by donating money to Ethiopia Millennium dam. From the three sections a total of 2364 birr has been donated and separately grade 9 section A students has contributed 771 birr and each students in average contributed 38.55 birr. In this section equal number of girls and boys were participated. In grade 9 in section B, students had contributed 837 birr and each students in average contributed
41.5. In section $\mathrm{B}, 7$ girls and 13 boys participated. In section $\mathrm{C}$, students had contributed 576 and each students in average contributed 37.80 birr. In section C, 11 girls and 9 boys participated.

c) Students' Model at Level 3: Millennium Dam MEA: Twelve teams of students were at this level. They were similar to teams at level 2, but they used more than three models like sum, mean and mode or median and mode. They worked on more than three variables on the provided data. For example, one team of students wrote a report working on four variables: sex of the students, amount of money contribution, sources of money contribution and sections of a student as shown below in the news. The students had used mean and mode to prepare the news; however, they could not identify the mean was affected by extreme values. They did not use the age of the students from the provided data to satisfy the client's need. In their report, they used figures like 39.9834 birr which may confuse listeners, since it is not common way to describe currency with four decimal places. The report presented by the team of the students' model on Millennium dam at Level 3 was given below.

NEWS: First the Headlines! Students in School A have contributed money for the Millennium dam. Students in three grade 9 sections contribute 2399 birr and 32 girls and 28 boys take part in the contribution. All students in average contributed 39.9834 birr. The sources from where students get the money for the dam contribution include families, friends, uncle, brother and the like. Out of these sources most students contributed from their pocket and they are 24 students. To finalize the news, students' contribution for the Millennium dam is encouraging.

d) Students' Model at Level 4: Millennium dam MEA: One team of students was at this level. The team identified that one student in section B had contributed 200 birr which attributed section B students' contribution to be the highest among the three sections as shown below in the news presented by the team of students. The team had used models like sum, extreme value, median and range. They had used variables such as students' age, sex, students' contribution of money, and students sections. They used the provided data and variables except money source to prepare the report. They recognized the highest value which could affect the mean of section B contribution. This created an opportunity to teach the median is more appropriate than mean, whenever data contain extreme values or outliers. The report presented by the team of the students' model on Millennium dam at Level 4 was given below.

NEWS: Here is the news! First the headlines! From three grades 9 sections, 28 girls and 32 boys had contributed money for the Millennium dam. The girls' participation is encouraging. Students' ages in the three sections are between 13 and 22. From the three sections, students in section B contribute the highest amount, because one student has contributed 200 birr. The students contributed 2399 birr. In average, a student contributes close to 35 birr. We ask, your excuse, not showing you the video. We have finished the news and invited you to watch the rest programs! 


\subsubsection{Students' Models for Tourist MEA}

The third MEA is on Tourist with title 'Ethiopia's Historical \& Natural Tourist Attractions' is given as a reading homework to students and followed by readiness or warm up questions for discussion such as: What does it tells you about the temperature in Addis when it says in an average the temperature is 61 degrees Fahrenheit? What do you think the temperature in Addis Abeba might be for 6 different days in the year? Why do you make these choices? Next students were given a data table on 'the climate data for the four tourist attraction sites' and asked to write a report for the tourist describing and comparing the climate data for the four tourist attraction sites telling them what type of clothes they should wear and what type of food(drinks) they should take or have. Therefore, below are the responses of students' model at different levels.

a) Students' Models at Level 1: Tourist MEA: Two teams of students were at this level. For example, a team of students gave general information on what clothes and shoes to wear, what food to eat and what drinks to drink, but they barely used data in their report to meet the client needs. The report presented by the team of the students' model on Tourist MEA at Level 1 was given below.

Dear Tourist, it is advisable that a tourist visit a country in September because the weather condition is conducive. When the tourist wants to visit a country, he should not bring clothes for cold weather, that is, he/she should bring light clothes. The shoes should be Sandals as there is no snow in the tourist sites. The tourist needs to bring an umbrella in case it rains. Besides, the tourist should bring fast foods and cold drinks. M.D $=28+23+35+23 / 4=23 \mathrm{M} . \mathrm{D}=/-5 /+/-7 /+/-5 /$ $+/ 0$ / divided by 4 equals 7 and M.D $=1.25$

b) Students' Models at Level 2: Tourist MEA: Eight teams of students were at level 2 . They used only one model which was range to describe the average annual temperature of two tourist attraction sites out of the four sites. They used partial data of the provided data and they tried to give information on two tourist attractions sites. The reports needed further refinements using more variables and data to furnish the tourist with good information for the four tourist sites. The report presented by the team of the students' model on Tourist MEA at Level 2 was given below.

Dear Tourist, Welcome to the attractive tourist sites of Ethiopia! We would like you to introduce two historic tourist attraction sites in Ethiopia. The two sites are known as Harar and Aksum. Harer is a city protected by stone wall and it is recognized by UNESCO. The people of Harer are well known for their hospitality and love. Both Christian and Muslims have lived in Harmony for centuries. Harer is found at an altitude of $55 \mathrm{~m}$ above sea level. The range of average temperature and rain days for a year in Harer is 5 degree centigrade and 9 respectively. Axum is a city well known for its obelisks for example one obelisk has a height of 33 meters. Aksum is found at an altitude of $2355 \mathrm{~m}$ which is at higher altitude than Harar. The range of average temperature and rain days for a year in Harer is 3 degree centigrade and 9 respectively. Dear tourist, Harar is hotter than Axum. You need to visit both places, because both of them are historical places and their social life and culture are interesting. Good Luck!

c) Students' Models at Level 3: Tourist MEA: Eight teams of students were at level 3 on Tourist MEA. For example, a team of students at this level used two models (range and bar graphs) to give information to the tourists using the provided data. They tried to present the data using bar graphs and range on average annual temperature on the two tourist attraction sites. The report and bar chart presented by the team of the students' model on Tourist MEA at Level 3 were given below.

Dear Tourist, We would like to give you reliable information about health requirement, customs, transport, time, currency, topography, etc. We would like to introduce two tourist attraction sites which are known as Axum and Lalibla. The range of the annual average temperature of Axum is 30c and the range of the annual temperature of Lalibla is 150c. So the Lalibla temperature is hotter than the Axum temperature. So if you go to Lalibla you must wear white or light clothes, since it will be hot there. You can see and compare the temperature difference using the pair of bar graphs as shown for the two sites. Come and visit us we will give you further information!
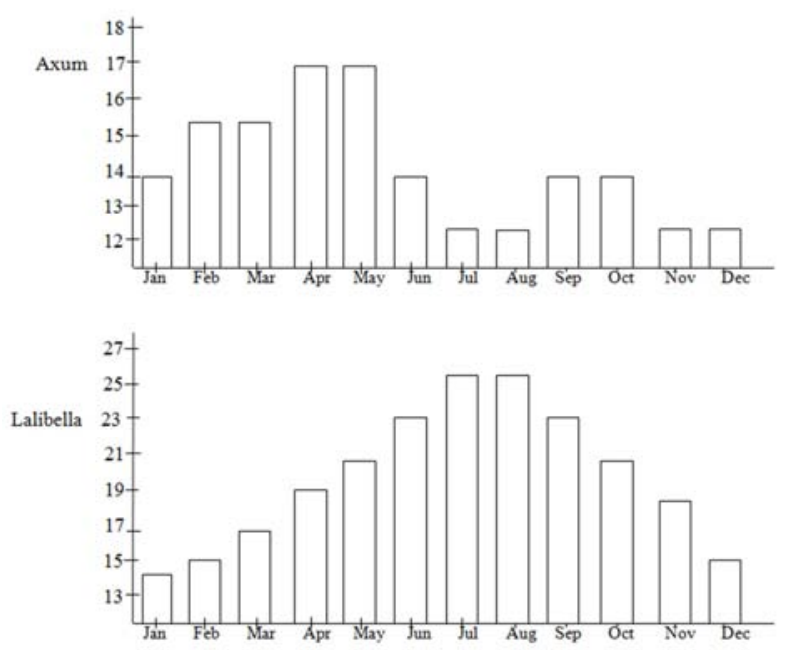

Figure 4. Team of students' Model on Tourist MEA at Level 3.

d) Students' Models at Level 4: Tourist MEA: One team of students was at level 4. Similar to team of students at level 3, the team had used range and bar graphs. But the team of students gave description on the rainfall amount of the four places in addition to using the average annual temperature. The report and bar chart presented by the team of the students' model on Tourist MEA at Level 4 were given below.

Things to do for Tourist! There are many things that we do for tourists; they may come from a country far from Ethiopia. Thus, they may not know our local languages that we have to translate the local language for them. We can also help them by carrying their goods, food, clothes and other necessary materials. We can also use range to show the tourist sites 
climate variations to give information for tourists.

- Axum- has low range because $18-15=30$ c and rainhigh $=11 \mathrm{~mm}$

- Lalibela-has high variation because $28-13=150 \mathrm{c}$ and rain-low $=1 \mathrm{~mm}$

- Gonder-has high variation because $35-23=120$ c and rain-low $=1 \mathrm{~mm}$

- Harar-low variation because $28-23=50$ c and rain high $=9 \mathrm{~mm}$

Dear tourists, welcome to the attractive sites of Ethiopia. Ethiopia is a country abundant with varied tourist sites which are attractive and you will have memories of these sites in your mind. We will say, welcome again! Now I am going to tell you about Ethiopian tourist sites. Ethiopia has many innumerable tourist sites that it is difficult to count in short period of time. Among the well known sites by tourism sector, we take today Axum, Lalibla, Gonder and Harar. We can see different amazing things at these places. Our dear tourists, if you want to come to Axum, you have to wear sweater, normal trousers and you need to have tea because there will be rain days. Again if you want to come to Lalibla, you have to wear t-shirt and need to have cold water and you have to have vegetable food because this place is very hot. As we notice from the graphs most months have high variation by temperature. At the end, please try to come to visit Ethiopian tourism.

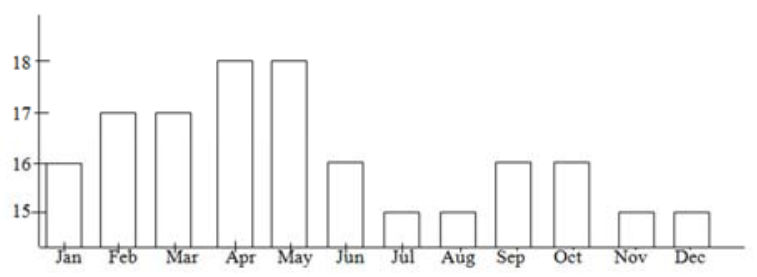

Figure 5. Team of students' model on Tourist MEA at Level 4.

e) Students' Models at Level 5: Tourist MEA: One team of students was at level 5. The team's report assumed to be sharable and reusable as the students used all the variables from the provided data and different models to describe the four tourist sites. They interpreted the data correctly within cultural contexts of the tourist sites like wearing style, social life of the people. They presented the information as if it was given in FM radio transmission. The report presented by the team of the students' model on Tourist MEA at Level 5 was given below.

This is Ethiopian FM RADIO! Dear tourists, first welcome to Ethiopia! We are happy to announce you that you will be happy for visiting Ethiopia, the country which has several historic, cultural and wildlife tourist attraction sites. Among the cities for tourist attractions I will give you important information on Harer and Gonder. And Helen will give you information about the attractive tourist sites of Lalibla and Axum. Please be with us! Based on data, Harer is located at an altitude of $55 \mathrm{~m}$ above sea levels. It is known for its people kindness and the city is called a 'love country'. And thus, this culture is closer to Brazilian culture and that many Brazilian come to visit Harar. The range of the average temperature for
Harar for a year is 5 degree centigrade with medium temperature. Thus, we need to wear light clothes like traditional Harar clothes called 'dereya'. When we look at the rainfall amount it has a standard deviation of $\sqrt{6.24}$. When we go to Gonder, it is located at an altitude of $380 \mathrm{~m}$ above sea levels and it is a city that we found several historic and cultural places to visit. The range of the average temperature for Gonder is 12 degree centigrade for a year with hot temperature. The standard deviation of the rainfall amount of Gonder for the year is $\sqrt{2.39}$. Now, Helen will present you information on other two cities.

Thank you Hanan! I will present you information on the great Ethiopian cultural Heritage placed called Aksum and Lalibla. Axum is a place where it attracts many tourists in the world and located at an altitude of $2355 \mathrm{~m}$. The range of average temperature for Axum is 3 degree centigrade which means it is not a hot place. The standard deviation of the rainfall amount is $\sqrt{14.85}$ and you can wear whatever cloths you like. When we see Lalibla, it has range of average temperature of 15 degree centigrade. The people who lived in Lalibla often wear white clothes to reflect the sun light radiation. You could also stay there wearing light clothes suitable for the weather condition. Lalibla is located at an altitude of $74 \mathrm{~m}$ from sea level and the standard deviation of the rainfall amount is $\sqrt{1.34}$. Thank you for staying with us! We will meet in another program.

Table 3 using Quality Assurance Guide for the four MEAs indicate that the percentage of number of teams of students' solution at level 1, 2, 3 and 4 were $10 \%, 38.8 \%, 45 \%$ and $5 \%$ respectively. Only one team of students' solution was considered at level 5 across the four MEAs. The majority of teams of students were at level 2 and 3.

Table 3. Number of teams' at the five performance levels for the four MEAs.

\begin{tabular}{lllll}
\hline Performance Level & $\begin{array}{l}\text { MEA-1 } \\
\text { f (\%) }\end{array}$ & $\begin{array}{l}\text { MEA-2 } \\
\text { f (\%) }\end{array}$ & $\begin{array}{l}\text { MEA-3 } \\
\text { f (\%) }\end{array}$ & $\begin{array}{l}\text { MEA-4 } \\
\text { f (\%) }\end{array}$ \\
\hline $\begin{array}{l}\text { Level one: Requires } \\
\text { Redirection }\end{array}$ & $3(15 \%)$ & $2(10 \%)$ & $1(5 \%)$ & $2(10 \%)$ \\
$\begin{array}{l}\text { Level two: Requires major } \\
\text { extension or revision }\end{array}$ & $7(35 \%)$ & $8(40 \%)$ & $8(40 \%)$ & $8(40 \%)$ \\
$\begin{array}{l}\text { Level three: Requires } \\
\text { editing and revision }\end{array}$ & $9(45 \%)$ & $9(45 \%)$ & $\begin{array}{l}10 \\
(50 \%)\end{array}$ & $8(40 \%)$ \\
$\begin{array}{l}\text { Level four: Useful for the } \\
\text { specific data given }\end{array}$ & $1(5 \%)$ & $1(5 \%)$ & $1(5 \%)$ & $1(5 \%)$ \\
$\begin{array}{l}\text { Level five: Shareable and } \\
\text { reusable }\end{array}$ & $0(0 \%)$ & $0(0 \%)$ & $0(0 \%)$ & $1(5 \%)$ \\
\hline
\end{tabular}

\subsection{Follow up Activities}

a) Follow up Activities for Safe-Water MEA. Students did the following follow up activities on Safe-Water MEA: distinguishing distribution, little or a lot variability and SafeWater MEA extension problem. Students in a team of three or four compared different distributions of dots plots and explained possible reason why students' score in mathematics could differ using center and variation informally as shown in Figure 6. Students were also introduced the concept of variability informally by asking 
them to describe whether a variable had a little or a lot of variability that could measure about themselves on a daily or weekly basis and examine over a period of week or month.
Finally, revisiting Safe-Water MEA as an extension problem, student was given an individual assignment to write a report on safe drinking water in their community.

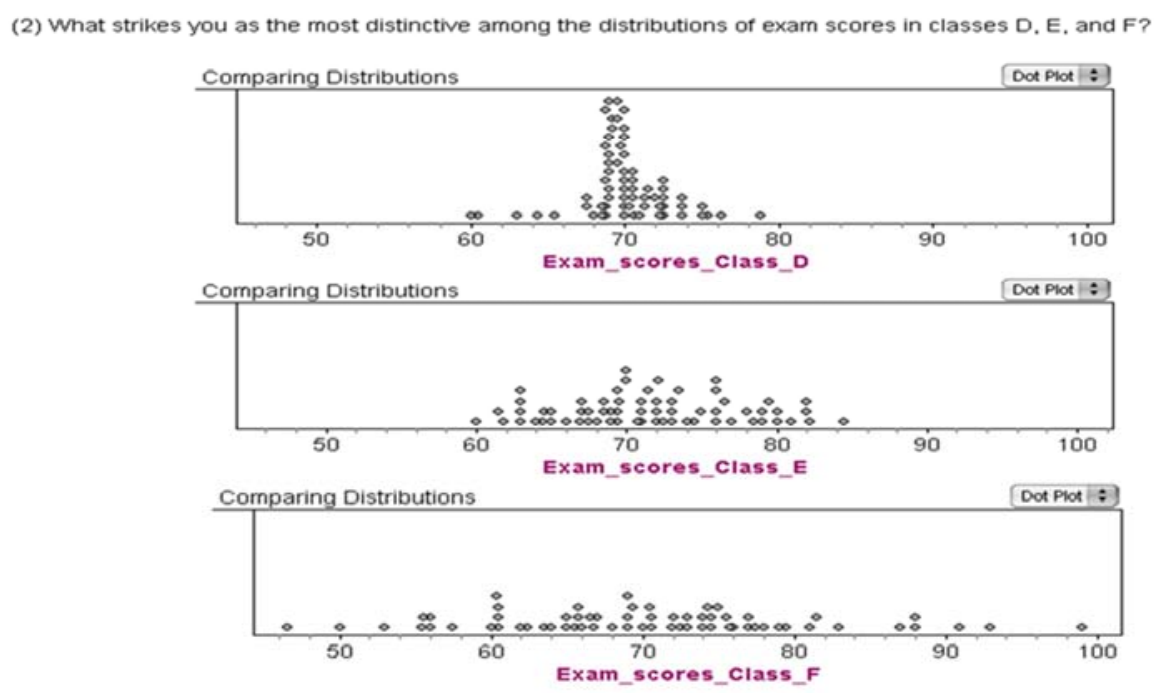

Figure 6. Comparing data distribution using dot plots.

b) Follow up Activities for Millennium Dam MEA. Students did the following Millennium Dam MEA follow up activities: choosing appropriate measure of center and Post-it Note activities. On choosing appropriate measure of center, students used the students' survey data by using graphs to decide which 'typical' value (mean or median) is appropriate examining a graph of distribution of variable. Students in their team did Post-it Notes activities to get sense of the mean as the 'balance' point as a representative of data and to show a median is not affected by extreme values. Further, students were introduced the concept of mean deviations on the Post-it Notes activity investigating the distance of each data points from the mean. For example, they showed the mean age of 10 students was 21 by explaining that the mean might not be the age of one of the students in the data sets. That is, they were able to move all post-it notes, yet the mean age was still 21 years as shown in Figure 7.

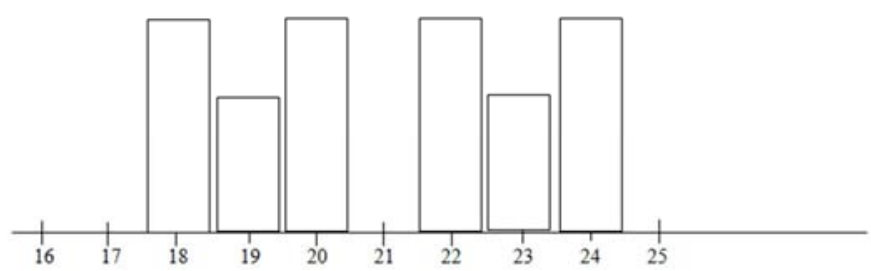

Figure 7. Team showing none of students age is 21 but mean is 21

c) Follow up Activities for Tourist MEA. One extension problem on Football MEA was to write a report or a news using statistical concepts on top ten provided data statistics for European and Ethiopian football clubs (English-Premier League, Spain-La Liga, Italy-Seria A, GermanyBuendeseliga and Ethiopia-Ethio League). In 'How big is your head?' follow up activity, each team of students' was given a plastic meters and collected data on head circumference for each member of the team. One student from each team wrote the team data on the blackboard and one student was selected to measure the head circumference of every student in the class.

Students were asked what the typical head circumference was looking at the distribution of the two data sets using dot plots. Students compared the two dot plots with respect to center and spread. Then, the students were asked what could be the possible reason for the variability of the data in the measurements of neck circumferences. Students were elicited why the variation existed and discussed the sources of data variability such as natural and measurement variability.

As extension to Tourist MEA, students described variation of weather data for three Towns for five consecutive days from TV, Radio or newspaper. Lastly, teams of students had compared the size of standard deviation in pair of histogram visually without calculating the standard deviation as shown in Figure 8.

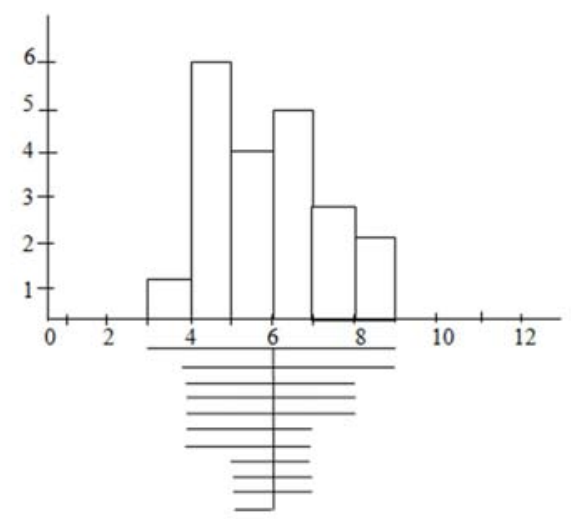




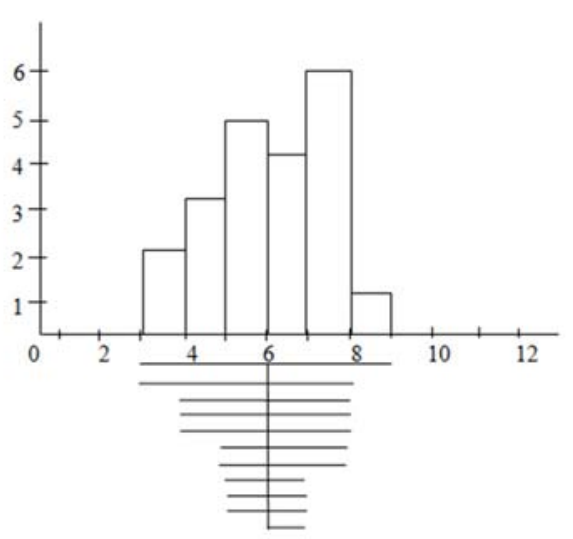

Figure 8. Students'solutions comparing standard deviation using histogram.

\subsection{Results on Achievement Test}

A descriptive analysis including sample means, standard deviation, and independent sample t-test were conducted to test hypotheses based on Skewness-Kurtosis normality test at $\alpha=0.05$ significance level to compare scores of students' using achievement tests on prior knowledge, procedural and conceptual understanding between students who learned descriptive statistics using Modeling and Non-modeling Approach. The prior knowledge test was taken as a pretest and achievement tests on procedural and conceptual understanding of descriptive statistics was taken as posttests.

From Table 4 below, inspection of the two groups means indicated that the average conceptual understanding achievement test for Non-modeling students (8.08 and 7.88 for school A and B respectively) is significantly lower than the score (9.50 and 9.10 for school A and B respectively) for students who have learnt using Modeling Approach. Table 4 shows there was statistically significant difference between students who have learnt using Modeling Approach and Nonmodeling Approach on conceptual understanding of descriptive statistics achievement test, $(\mathrm{p}=.004$ at $\alpha=.05)$ in School A and ( $\mathrm{p}=.005$ at $\alpha=.05)$ in School B. The effect sizes (Cohen's d) were approximately .67 and .64 for school A and B respectively. Students who learned using Modeling Approach did not differ significantly from students who learned with Non-modeling Approach on achievement test on procedural understanding of descriptive statistics $(p=.424$ and $\mathrm{p}=.099$ ). There was no significant difference between the two groups in the pretest prior knowledge in school A and B.

Furthermore, Table 4 showed that students' procedural and conceptual understanding of descriptive statistics were significantly different on the achievement tests for modeling group $(\mathrm{p}=.014$ and $\mathrm{p}=.004)$ unlike the Non-modeling group $(\mathrm{p}=.280$ and $\mathrm{p}=.111)$ in school $\mathrm{A}$ and $\mathrm{B}$. Looking at the two dependent variables score means, the average score conceptual understanding achievement test is ( 8.03 for school A and 7.88 for school B) was lower than the score (9.50 and 9.10 for school A and B respectively) for students who had learnt using Modeling Approach.

Combing two sections of students who had learned using Modeling Approach, comparison was made across groups by combining another two sections of students who had learned using Non-modeling Approach. Table 4 also showed that students who had learnt using Modeling Approach were significantly different from students who had learnt using Non-modeling on both conceptual understanding $(p=.000)$ but not on procedural understanding $(\mathrm{p}=.105)$ of descriptive statistics achievement test across the groups in both schools. Comparing the two groups means showed that the average conceptual understanding achievement test for Non-modeling students (7.98) was significantly lower than the score (9.30) for students who had learned using modeling approach with effect size 0.66 .

Table 4. Comparison of modeling and non modeling class of students'scores in two aggregate Schools.

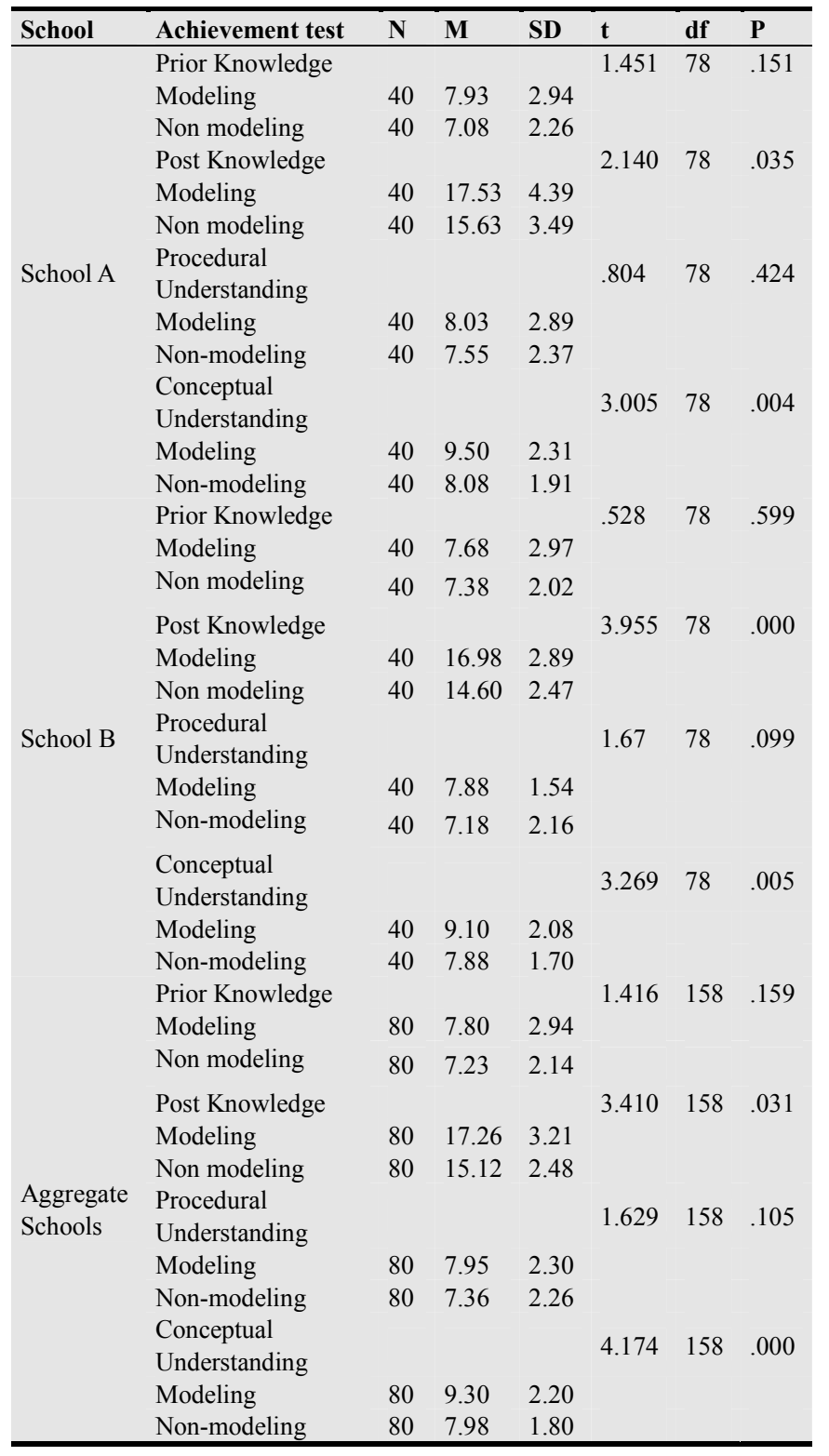

\section{Discussion}

Students' in a team worked on multi data sets and on multi variables to write reports and letters. Learning statistics is not 
only doing, but also involves describing and interpreting situations statistically [20]. The finding of the study suggests students can draw conclusion informally from data in a context on MEAs as contents of students' reports showed. Students can construct, test and revise their models by expressing their thinking through representation systems [17]. The multiplicity of students' reports on MEAs showed students can develop authorships of ideas than relaying simply on text books and teachers.

The finding also suggested students found the MEAs relevant to their life and they were 'hard fun' activities. Students were able to go through the modeling cycle and they were able to think 'outside of the subject box' in multidisciplinary areas. Statistics is at an intersection of many subjects, since all subjects will use some data to work with concepts. This is an opportunity to all allow students to work with a team in multi-disciplinary area which is the ability and understanding needed beyond school in an age of information [6]. Students get used to the statistical inquiry cycle doing MEAs [28]. By working on real world problem, a set of data and the need for a solution, students would experience the statistical inquiry cycle.

Much emphasis is given to Science, Technology, Engineering and Mathematics Education in Ethiopia Education System [13]. Hence, Modeling Approach would come into spotlight to bring together different disciplines. Working on relevant non-routine problems like MEAs starting from lower grades would create opportunities to students to prepare them for their future careers like engineering and other sciences. The finding of the study among others indicated it is possible to develop students' modeling experiences from early grades $[6,7,20]$.

According to Freire [46], it is better if students select the investigative themes by themselves than investigative themes assigned by a teacher. Students had developed their critical understanding of descriptive statistics using statistics as critical tool towards solving the socio-cultural problems. Students were working on themes that arose from educational to economic to social life and culture problems. Students were presenting awareness program on avoiding copying during examination, avoiding bad addiction habits, keeping dental care and body weight regularly, and resolving problems on gender issues.

Gustine [47] used both statistics and mathematics with social agency, but there were a number of subtle similarity and differences in this study from his approach. Gustine chose the investigative themes for students, but in the Modeling Approach, students first worked on MEAs problems with investigative themes having relevance with socio-cultural problems. Then, students selected the themes by themselves towards helping others with sympathetic understanding. In the Modeling Approach, students learned according to the time plan of the lessons on descriptive statistics set by Ministry of Education on Grade Nine curriculum syllabuses. One of the advantage of MEA was it took not more than two or three periods unlike other nonroutine problem solving tasks that requires an extended

\section{period of time.}

Students' were able to develop their critical productive disposition towards statistics. Students' had used different entertainment and fun using statistics as a critical tool to give an awareness program on their project themes. Students had used drama, live interview, fashion show, poems which could add value to their productive dispositions towards statistics as a tool that could be used in their everyday life to solve their own and society's problems. Students could enhance the statistical thinking which basically emphasis making conclusion based on data in a context.

Many defenders raises practical issues by claiming that it is not possible to teach statistics using Modeling Approach due to time constraints and content coverage in the school programs. Of course, some problem-driven curriculum may take longer period of time than the allotted time in schools [5]. However, as this study among others showed, MEAs did not take longer more than one or two periods that time constraints may not be a problem $[5,20]$. Students need to develop both content and process objectives for learning descriptive statistics. Most importantly, the best possible ranges of problem types that involve routine and non-routine problems need to be used. Students could learn on big ideas of descriptive statistics using MEAs based on few design principles as this study suggests. Further, students could be benefited more if they do extended open-ended projects to experience statistical investigative processes that could save enough time to meet the process objectives as this study findings suggested.

Students were able to create fun and different styles when they wrote reports and news on the MEAs. This could create positive dispositions towards statistics, because students were having fun in the class despite the fact that MEAs are cognitively challenging tasks. A study had showed that students would engage in statistics class if they are motivated and got some fun in the class [48]. Students found that working in MEAs were 'hard fun' to develop their dispositions towards statistics. Students were reporting their solution using news and letters in funny ways which had created students motivations to work on MEAs. Though data modeling was challenging, students were able to engage and preserve in completing the modeling cycle, because students got a chance to present their report in their own styles as observed in modeling class which is supported by similar research findings [42].

As a doctor inquires further tests to understand fully the patient case, the study administered achievement tests to investigate to what extent students understand descriptive statistics using Modeling Approach. The core finding of the study suggested students could enhance their conceptual understanding of descriptive statistics with medium effect size without compromising their procedural understanding of descriptive statistics using Modeling Approach. This finding is similar with other studies using problem-driven curriculum [49].

\section{Conclusion and Recommendations}

The topic presents a summative claim on what has been 
found related to the study purpose, aim and design. It addresses on how far the findings have answered the research questions. The topic presents concluding remarks on the degree of certainty with which the findings from the specific context could be generalized in contributing to answering the central question, and then it points out recommendations and suggestions for future research.

\subsection{Conclusion}

Students worked on relevant non-routine problem solving tasks called MEAs and representation systems to lay the basic foundations for important learning outcome in statistics education such as statistical literacy, reasoning and thinking. In an age of information, students at their youth age need to solve relevant non-routine problem solving tasks to enhance their critical understanding which could enable them to cope up with the nature of problems in daily life. Students could get a sense of social agency using statistics as a critical tool solving socio-cultural problems using data modeling.

The study revealed that students who learned using Modeling approach could enhance their understanding of descriptive statistics. Students' could elicit their models by externalizing thinking through representation systems working on MEAs and develop their models by testing, revising, and refining iteratively with follow up activities. The findings of this study are reminders that Modeling Approach more likely enhances students' understanding of descriptive statistics with similar school settings, but needs further efficacy study at different school settings and populations; it also needs large scale effectiveness study to meet the interests of stakeholders in an education system.

\subsection{Recommendations}

The researchers prepared the themes of MEAs selecting topical issues from the society. To set non routine interdisciplinary problems within the interest of all stakeholders, key stakeholders such as teachers, students, STEM educators, and social-agents should co-ordinate being evolving experts. The study was conducted in nontechnological environment, but technology will further strength the use of Modeling Approach making the representation system dynamic. Statistics Educators and researchers will play a major role informing what big ideas and cognitive process need to include in the curriculum. Social-agents also identify investigative themes that could create sense of social agency solving social problems. Modeling Approach curriculum drives its epistemology of constructing, testing and revising models from engineering as they are heavy users of mathematics and the nature of problems beyond school are of these types [20].

After the problem-driven curriculum is set, then it is operationally implemented in the Modeling Instructional Approach. The main elements in interaction in Modeling Instructional Approach are the modeling tasks, students and the teacher. The tasks involve MEAs which are non-routine problem solving tasks. The study suggests that students find them relevant. If the tasks are not relevant, the teacher and other stakeholders need to find sensitive and timely issues going back to design the curriculum. Thus, the curriculum and the instruction would inform each other back and forth. Problem-driven curriculum using Modeling Approach would give a framework to see what goals drive every action in the instruction.

Then, teacher also makes interpretation of students' models on MEAs. Statistics involves not only doing analysis on data sets, but also it involves interpreting realistic complex situations. Finally, teachers could assess students' individual cognition using assessment tool that asks statistical reasoning.

The finding of this study suggests that if there is a synergy of curriculum, instruction and assessment using Modeling Approach in an education system, students likely could enhance their understanding of descriptive statistics. This is preliminary research which could inform problem solving policy in secondary mathematics curriculum, but further research is needed to inform the policy better as discussed below.

\section{References}

[1] English, L. D. (2013a). Complex modeling in primary and middle schools years: An interdiscplinary approach. In G. A. Stillman, G. Kasier, \& J. P. Werner Blum, Teaching mathematical modelling: Connecting research to practice (pp. 491-503). New York.London: Springer.

[2] Kaiser, G., \& Schwarz, B. (2006). Mathematical modeling as a bridge between school and university mathematics. ZDM, 196-208.

[3] Stillman, G. A., Kasier, G., Blum, W. \& Brown, J. (2013). Teaching mathematical modeling: Connecting research to practice. London: Springer.

[4] Kaiser, G., Blohomhoj, M., \& Siriraman, B. (2006). Towards a didactical theory for mathematical modeling. ZDM, 82-85.

[5] Chamberlin, S. A., \& Coxbill, E. (2012). Using ModelElicting Activities to introduce upper elementary students to Statistical Reasoning and Mathematical Modeling. In L. H. Mayes, Quantitative reasoning and mathematical modeling: A driver for STEM integrated education and teaching in context. (pp. 169-179). Wyoming: Wyoming Insititute for the Study of Mathematics Education, Laramie, WY.

[6] English, L. D. (2013b). Surviving an avalanche of data. Teaching Children Mathematics, 364-372.

[7] Kinnear, V. (2013). Young children statistical reasoning: A tale of two contexts. A dissertation thesis. Queensland Technology University of Technology, Australia.

[8] Sriraman, B., \& English, L. (2010). Theories of Mathematics Education: New Frointers. Springer.

[9] Cobb, G. W. (2007). One possible framework for thinking about experential learning. International Statistical Review, 336-347. 
[10] Garfield, J., \& Ben-Zvi, D. (2008). Developing students' statistsical reasoning: Connecting research and teaching practice. London: Springer.

[11] Ministry of Education (MoE) (2009a). Education and development, Ministry of Education, Addis Ababa, Ethiopia.

[12] Ministry of Education (MoE) (2010a). Education Sector Development Program IV (ESDP IV): Program action plan, Federal Ministry of Education, Addis Abeba, Ethiopia.

[13] Ministry of Education (MoE) (2010b). Mathematics teacher's guide for Grade 9, Ministry of Education, Addis Ababa Ethiopia.

[14] Micheal, K. \& O'Connell, A. (2014). Statistics Education in Ethiopia: Successes, challenges and opportunities. In K. Makar, B. de Sousa \& R. Gould (Eds.) Sustainably in Statistics Education. Proceedings of the ninthth International Conference on Teaching Statistics (ICOTS-9, July, 2014, Flagstaff, Arizona, USA). Voorburg, The Netherlands: International Statistical Institute.

[15] Kaiser, G. (2010). Introduction: ICTMA and the reaching of modeling and application. In L. Richard, P. L. Galbraith, C. R., Haines, \& A. Harford (Eds.), Modeling students' mathematical modeling competencies (PP. 1-2). New York: Springer.

[16] Lesh, R., \& Doerr, H. (Eds.). (2003). Beyond constructivism:Models and Modeling Perspectives on mathematices problem solving, learning and teaching. London: Lawrance Erlbaum Assocciate Publisher. [17] Lesh, R., \& Fennewald, T. (2010). The nature of Models and Modeling: Introduction to part I modeling: What is it? why we do it? In R. Lesh, P. L. Galbraith, C. R. Haines, \& A. Hurford, Modeling students' mathematical competencies (pp. 5-12). London: Springer.

[17] Kaiser, G., \& Sriraman, B. (2006). A global survey of international perspectives on modeling in mathematics education. ZDM, 38(3), 302-310.

[18] Ferri, R. B., \& Lesh, R. (2013). Should interpretation systems considered to be Models if they only function implicitly. In G. A. Stillman, G. Kaiser, \& W. Blum, Teaching mathematical modelling: Connecting research and practice (pp. 57-66). New York; London: Springer.

[19] Lesh, R. (2012). Research on Model and Modeling and implication for common core state curriculum standards. In L. $\mathrm{H}$. Mayes, Quantitative reasoning and mathematical modeling: A driver for STEM integrated education and teaching in context. (pp. 169-179). Wyoming: Wyoming Insititute for the Study of Mathematics Education, Laramie, WY.

[20] Lesh, R., Yoon, C., \& Zawojewski, J. (2007). John Dewey revisited-Making mathematics practical versus making practice mathematical. In R. A. Lesh, E. Hamilton, \& J. J. Kaput, Foundations for the future in Mathematics Education (pp. 315-348). Mahwah, NJ London: Lawrance Erlbaum Associate Publisher.

[21] Glasersfeld, E. v. (2003). Book review: Beyond constructivism, Models and Modeling Perspectives on mathematics problem solving, learning and teaching. ZDM, 325-329.

[22] Hamilton, E., Lesh, R. Lester, F. \& Yoon, C. (2007). The use of reflection tool in building personal models. In R. Lesh, E. Hamilton, \& J. J. Kaput (Eds.), Foundations for future in
Mathematics Education (pp. 1-6). Mahwha: NJ: Lawrence Erlbaum.

[23] Magiera, M. T. (2013). An aluminium Bat Activity supports goals of STEM learning by engaging students in resourcful problem solving. Mathematics Teaching in the Middle School, 349-355.

[24] Diefes-Dux, H., Whittenberg, L., \& McKee, R. (2013). Mathematics modeling at the intersection of elementary mathematics, art and engineering Education. In L. D English \& J. T Mulligan (Eds.), Reconceptualizing early mathematics learning, advance in Mathematics Education, 309-325. doi:10.1007/978-94-007-6440-8_15

[25] Mousoulides, N. G., \& English, L. D. (2012). Modeling as a bridge between real world problems and school mathematics. The 12th International Congress on Mathematics Education, $1-10$.

[26] Shuman, L. J, Besterfield-Sacre, M. E, Bursic, K. M, Vedic, N. S., \& Siewiorek, N. (2012). CCLI. Model-Eliciting Activities, American Society for Engineering Education, 1-12.

[27] Wild, C., \& Pfannkuch, M. (1999). Statistical thinking in emperical enquiry. International Statistical Review , 223-265.

[28] Doerr, H. M., \& English, L. D. (2003). A modeling perspective on students' mathematical reasoning about data. Journal for Research in Mathematics Education, 110-136.

[29] Garfield, J., delMass, R. C., \& Ziefeller, A. (2009). Using Model-Eliciting Activities (MEAs) in statistics classroom. Roundtable Presentation at the Joint Statistical Meetings (pp. 1-7). Washington DC: University of Minnesota.

[30] Noll, J., Geberesenbet, M., \& Glover, E. D. (2012). A Modeling and simulation approach to informal inference:Successes and challenges. The 12th International Congress on Mathematical Education: Teaching and Learning of Statistics (TSG-12) (pp. 141-150). South Korea, Seoul: International Congress on Mathematical Education.

[31] Hjalmarson, M. A., Moore, T. J., \& delMass, R. (2011) Statistical analysis when the data is an image: Elicting student thinking about sampling and variability. Statistics Education Research Journal, 15-34.

[32] Pearl, D. K., Garfield, J. B., delMas, R., Groth, R. E., Kaplan, J. J., MaGowan, H., \& Lee, H. S. (2012). Connecting research to practice in a culture of assessment for introductory college level Statistics. [Online: http:// www.causeweb.org/research/guidelines/ResearchReport_DEC 2012.PDF].

[33] Schwartz, D. L., Sears, D., \& Chang, J. (2007). Reconsidering prior knowledge. In M. Lovett and P. Shah (Eds.), Thinking with data (pp. 319-344). New York: Erlbaum.

[34] Lesh, R., Hoover, M., Hole, B., Kelly, A., \& Post, T. (2000). Principles for developing thought-revealing activities for students and teachers. In A. Kelly \& R. Lesh (Eds.), Handbook of research in Mathematics and Science Education (pp. 113-149). Mahwah, NJ: Lawrence Erlbaum and Associates.

[35] World Bank (2006). Assessing national achievement levels in education. (Eds.) Greaney V. \& Kellenghan.

[36] Ethiopian National Examination Agency (2010). Ethiopian First National Learning Assessment (Grade 10 and 12). 
[37] Ethiopian National Examination Agency (2013). Ethiopian Second National Learning Assessment (Grade 10 and 12).

[38] Meletiou-Mavrotheris, M. (2007). The Formalist mathematical tradition as an obstacle to stochastical reasoning. In K. Francois, \& J. P. V Bandegem (Eds.) Philosophical dimensions in Mathematics Education (PP. 131155). Springer

[39] Gouvea, J. S., Sawtelle, V., Geller, B. D., \& Turpen, C. (2013). A framework for analyzing interdiscplinary tasks: Implication for student learning and curricular design. CBE- Life Science Education, 187-205.

[40] Creswell, J. W. (2014). Research design: Quantitative, qualitative, mixed Method (4th ed.). Thousand Oaks, CA: Sage Publication.

[41] Boaler, J. (2009). When politics took the place of inquiry : A response to the national mathematics advisory panel's review of instructional practice. Educational Researchers, 588-594. doi:10.3102/0013189X08327998

[42] Campell, D. T., \& Stanley, J. C. (1963). Experimental and quasi Experimental designs. USA: Houghton Mifflin Company.
[43] Yin, R. K. (2003). Case study research: Design and methods (3rd ed.). Thousand Oaks: Sage Publications.

[44] Chamberlin, S. A. \& Moon, S. M. (2005). Model-Eliciting Activities as a tool to develop and identify creatively gifted mathematicians. The Journal of Secondary Gifted Education, $37-47$.

[45] Freire, P. (1970). Pedagogy of the Oppressed. The Seabury Press. New York.

[46] Gutstein, E. (2006). Reading and writing the world with mathematics: Towards a pedagogy for social Justice. USA: Routeldge.

[47] Lesser, L. M., Wall, A. A., Carver, R. H., Pearl, D. K., Martin, N., Kupier, S., . . . Weber, J. J. (2013). Using fun in statistics classroom: An exploratory study of college instructors' hesitation and motivations. Journal of Statistics Education , 1-3.

[48] Schoenfeld, A. (2004). The math wars. Educational Policy, 256-286. 